\title{
Endovascular revascularization for aortoiliac atherosclerotic disease
}

\author{
This article was published in the following Dove Press journal: \\ Vascular Health and Risk Management \\ 29 March 2016 \\ Number of times this article has been viewed
}

\author{
Vikas Aggarwal' \\ Stephen W Waldo ${ }^{2,3}$ \\ Ehrin J Armstrong ${ }^{2,3}$ \\ 'Prairie Heart Institute, St John's \\ Hospital, Springfield, IL, ${ }^{2}$ Section \\ of Cardiology, Denver Veterans \\ Affairs Medical Center, ${ }^{3}$ Section of \\ Cardiology, University of Colorado, \\ Aurora, CO, USA
}

\begin{abstract}
Atherosclerotic iliac artery disease is increasingly being treated with endovascular techniques. A number of new stent technologies can be utilized with high long-term patency, including self-expanding stents, balloon-expandable stents, and covered stents, but comparative data on these stent types and in more complex lesions are lacking. This article provides a review of currently available iliac stent technologies, as well as complex procedural aspects of iliac artery interventions, including approaches to the treatment of iliac bifurcation disease, long segment occlusions, choice of stent type, and treatment of iliac artery in-stent restenosis.

Keywords: peripheral artery disease, iliac artery, balloon expandable stent, self expanding
\end{abstract} stent, covered stent, claudication, endovascular

\section{Introduction}

The iliac arteries constitute a common anatomic site for obstructive atherosclerosis, accounting for approximately one-third of all symptomatic peripheral artery disease. $^{1,2}$ Revascularization options for aortoiliac disease include endovascular therapy and surgical bypass grafting. Newer-generation stents and endovascular techniques for crossing complex occlusions now afford similar long-term patency compared to surgical bypass grafts. Endovascular stent placement has therefore become the most frequent revascularization strategy in patients with symptomatic iliac artery stenosis. ${ }^{3-5}$

Several types of balloon-expandable, self-expanding, and covered stents are available for endovascular treatment of iliac disease. This article reviews currently available iliac stents, followed by an overview of current data on treatment techniques and outcomes of endovascular recanalization of iliac artery occlusive disease, with emphasis on the treatment of iliac bifurcation disease, long segment occlusions, and iliac artery in-stent restenosis.

\section{Stent types}

Stents available for use in the aortoiliac arteries can be divided into balloon-expandable stents, self-expanding stents, and covered stents. Although significant data exist for each stent type, most clinical studies have included patients with relatively less-complex disease. In addition, little comparative data exist between stent types. Table 1 lists the commercially available stents in the US that are commonly used in the iliac arteries, with clinical data on the outcomes specific to each stent type. Table 2 lists the technical data regarding commonly used stent types.
Correspondence: Ehrin J Armstrong Section of Cardiology, Denver Veterans Affairs Medical Center, 1055 Clermont Street, Denver, CO 80220, USA Tel + I 4153122480

Email ehrin.armstrong@gmail.com (c) (1) (5) ( 2016 Aggarwal et al. This work is published and licensed by Dove Medical Press Limited. The full terms of this license are available at https:///www.dovepress.com/terms. cc) you hereby accept the Terms. Non-commercial uses of the work are permitted without any further permission from Dove Medical Press Limited, provided the work is properly attributed. For

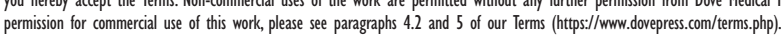


Table I Major studies of currently available iliac artery stents

\begin{tabular}{|c|c|c|c|c|c|c|}
\hline Study & Stent name & Stent type & $\begin{array}{l}\text { Number of patients; } \\
\text { number of lesions }\end{array}$ & Target lesion length & Primary patency & TLR, I year \\
\hline Melodie $^{8}$ & Express LD & $\begin{array}{l}\text { Balloon } \\
\text { expandable }\end{array}$ & $\begin{array}{l}151 \text { patients; } \\
163 \text { lesions }\end{array}$ & $32.0 \pm 21.7 \mathrm{~mm}^{\mathrm{a}}$ & $\begin{array}{l}92.1 \% \text { at } 6 \text { months; } \\
87.8 \% \text { at } 2 \text { years }\end{array}$ & \\
\hline ACTIVE $^{9}$ & Assurant & $\begin{array}{l}\text { Balloon } \\
\text { expandable }\end{array}$ & $\begin{array}{l}\text { I23 patients; } \\
\text { I59 lesions }\end{array}$ & $29.4 \pm 14.7 \mathrm{~mm}^{\mathrm{a}}$ & $99.2 \%$ at 9 months & \\
\hline Mobility" & Omnilink & $\begin{array}{l}\text { Balloon } \\
\text { expandable }\end{array}$ & I23 stent; I2I PTA & 45 mm stent; 44 mm PTA & $68 \%$ stent; $61 \%$ PTA & I4\% stent; I $8 \%$ PTA \\
\hline Krol et al ${ }^{12}$ & Zilver & Self-expanding & 34 stent; 39 PTA & $82 \mathrm{~mm}$ stent; $65 \mathrm{~mm}$ PTA & $66 \%$ stent; $39 \%$ PTA & NR \\
\hline CRISP-US'4 & $\begin{array}{l}\text { SMART; } \\
\text { Wallstent }\end{array}$ & Self-expanding & $\begin{array}{l}\text { I02/I I8 SMART stent; } \\
\text { I0I/I I } 4 \text { Wallstent }\end{array}$ & $\begin{array}{l}24.7 \pm 15.6 \mathrm{~mm}(\text { SMART } \\
\text { stent); } 24.5 \pm 19.1 \mathrm{~mm} \\
(\text { Wallstent })^{\mathrm{a}}\end{array}$ & $\begin{array}{l}94.7 \% \text { at } 12 \text { months } \\
\text { with SMART stent; } \\
91.1 \% \text { at I } 2 \text { months } \\
\text { with Wallstent }\end{array}$ & I3\% stent; $21 \%$ PTA \\
\hline Mobility ${ }^{15}$ & Absolute Pro & Self-expanding & I34 stent; 72 PTA & 70 mm stent; 64 mm PTA & $81 \%$ stent; $37 \%$ PTA & I $3 \%$ stent; $55 \%$ PTA \\
\hline Luminexx ${ }^{16}$ & Lifestar & Self-expanding & I34 patients; I 56 lesions & $25.7 \pm 18.2 \mathrm{~mm}^{\mathrm{a}}$ & $94.0 \%$ stent & $3.73 \%$ (at 9 months) \\
\hline Lammer et $\mathrm{al}^{18}$ & Viabahn & $\begin{array}{l}\text { Covered self- } \\
\text { expanding }\end{array}$ & 61 lesions & $69 \mathrm{~mm}$ & $91 \%$ at 12 months & \\
\hline iCARUS ${ }^{21}$ & iCAST & $\begin{array}{l}\text { Covered balloon } \\
\text { expandable }\end{array}$ & 165 patients & & & $2.9 \%$ (at 9 months) \\
\hline COBEST $^{20}$ & VI2; BMS & $\begin{array}{l}\text { Covered balloon } \\
\text { expandable }\end{array}$ & $62 / 83 \mathrm{VI} 2 ; 63 / 85 \mathrm{BMS}$ & & & $\begin{array}{l}2.4 \% \text { VI } 2 ; 15.8 \% \\
\text { BMS (TVR at } \\
\text { I8 months) }\end{array}$ \\
\hline
\end{tabular}

Notes: aData shown as mean \pm standard deviation.

Abbreviations: BMS, bare metal stent; COBEST, Covered Versus Balloon-Expandable Stent Trial; NR, not reported; PTA, percutaneous transluminal angioplasty; TLR, target lesion revascularization; TVR, target vessel revascularization.

\section{Balloon-expandable stents}

Balloon-expandable stents consist of a cylindrical scaffold constructed from metallic wire secured on an angioplasty balloon. Most balloon-expandable stents possess high radial force "hoop strength", but lack flexibility relative to selfexpanding stents. The prototypical Palmaz stent was constructed from stainless steel. ${ }^{6,7}$ However, newer-generation

Table 2 Commercially available stents for aortoiliac disease, with associated sizing

\begin{tabular}{|c|c|c|c|c|}
\hline Stent name & $\begin{array}{l}\text { Scaffold } \\
\text { material }\end{array}$ & $\begin{array}{l}\text { Introducer } \\
\text { sheath sizes } \\
\text { (Fr) }\end{array}$ & $\begin{array}{l}\text { Stent } \\
\text { diameters } \\
(\mathrm{mm})\end{array}$ & $\begin{array}{l}\text { Stent } \\
\text { lengths } \\
(\mathrm{mm})\end{array}$ \\
\hline \multicolumn{5}{|c|}{ Balloon-expandable stents } \\
\hline Express LD & Stainless steel & $6-7$ & $6-10$ & $17-57$ \\
\hline Assurant & $\begin{array}{l}\text { Cobalt- } \\
\text { chromium }\end{array}$ & 6 & $6-10$ & $20-60$ \\
\hline $\begin{array}{l}\text { Omnilink } \\
\text { elite }\end{array}$ & $\begin{array}{l}\text { Cobalt- } \\
\text { chromium }\end{array}$ & $6-7$ & $6-10$ & $12-59$ \\
\hline \multicolumn{5}{|c|}{ Self-expanding stent } \\
\hline Everflex & Nitinol & 6 & $6-8$ & 20-200 \\
\hline SMART ${ }^{\circledR}$ & Nitinol & 6 & $6-10$ & $20-100$ \\
\hline Zilver & Nitinol & 6 & $5-10$ & $20-140$ \\
\hline Absolute Pro & Nitinol & 6 & $6-10$ & $20-100$ \\
\hline Lifestar & Nitinol & 6 & $6-10$ & $20-100$ \\
\hline \multicolumn{5}{|l|}{ Covered stents } \\
\hline Viabahn & Self-expanding & $7-12$ & $5-13$ & $25-250$ \\
\hline $\begin{array}{l}\text { Atrium } \\
\text { iCAST TM }^{\text {TM }}\end{array}$ & $\begin{array}{l}\text { Balloon } \\
\text { expandable }\end{array}$ & $6-7$ & $5-10$ & $16-59$ \\
\hline
\end{tabular}

contemporary balloon-expandable iliac stents have a much improved mesh design with smaller cells and thinner struts (eg, cobalt-chromium alloy-based stents), lending greater flexibility while preserving excellent radial strength.

\section{Express LD stent}

The Express ${ }^{\mathrm{TM}}$ LD vascular stent (Boston Scientific, Inc, Marlborough, MA, USA) is a balloon-expandable stainless steel stent designed to be flexible and easy to deliver while still maintaining radial strength and radiopacity. The stent has platinum-iridium radiopaque markers premounted on an over-the-wire (OTW) noncompliant balloon.

The Express LD stent was evaluated in the prospective, single-arm MELODIE study. ${ }^{8}$ A total of 151 patients (163 lesions) with iliac disease and claudication (Fontaine classes II-III) received Express LD stents. The majority of lesions $(78.1 \%)$ were treated with a single stent, and successful implantation with $\leq 30 \%$ residual stenosis was achieved in $98 \%$ of lesions. A majority of these lesions were classified as Trans-Atlantic Intersociety Consensus (TASC) A (45.1\%) or TASC B (39.1\%); the preimplantation mean lesion length and diameter stenosis were $32.0 \pm 21.7 \mathrm{~mm}$ and $62.9 \%$, respectively. A relatively small fraction of lesions required predilation (22.1\%), and postdilation was performed in only $5.5 \%$ of cases. A total of $41.1 \%$ of the stents were placed in the common iliac artery (CIA) and $52.1 \%$ in the external 
iliac artery (EIA); 6.8\% of the stents extended from the CIA into the EIA. Reference vessel diameter ranged from $5 \mathrm{~mm}$ to $10 \mathrm{~mm}$ and at least one vessel infrapopliteal runoff was required for inclusion in the study.

At 6 months, the mean percentage luminal diameter loss by quantitative vessel analysis for the Express LD vascular stent was $16.2 \%$. Primary patency was $92.1 \%$ at 6 months and $87.8 \%$ at 2 years. The major adverse event rate, defined as device- or procedure-related death, target lesion revascularization (TLR), or device-related distal embolization that required hospitalization and/or subsequent intervention, was $6.3 \%$ at 6 months and $10.2 \%$ at 2 years. Overall, the Express LD stainless steel stent system met the criteria for noninferiority compared to the stainless steel Palmaz stent.

\section{Assurant stent}

The Assurant (Medtronic, Inc) iliac stent is a new-generation cobalt-chromium balloon-expandable system. Use of a cobalt-chromium alloy allows the device to have increased flexibility and a lower profile (given thinner struts) while maintaining radial strength and fluoroscopic visibility. Another feature of this stent platform is a small cell size designed to conform to the vessel wall and to provide scaffolding coverage, thereby minimizing tissue prolapse.

The Assurant stent was evaluated in the single-arm, prospective, multicenter ACTIVE study. ${ }^{9}$ The study enrolled 123 patients (159 CIA or EIA lesions) with claudication (Fontaine classes I-III). Target lesions were most often located in the CIA $(128 ; 80.5 \%)$. The mean reference diameter was $7.6 \mathrm{~mm}$, and the mean lesion length was $29 \mathrm{~mm}$. More than half of the lesions (57\%) showed moderate-to-severe calcification. Successful stent implantation was achieved in $97.5 \%$ of lesions (155/159). Approximately half (53\%) of the patients were treated with predilation, while the remainder had direct stenting. Overall, 171 stents were implanted and less than half (41\%) were postdilated. No dissections were identified after stent implantation. There were no device- or procedure-related deaths in the trial and no target limb loss.

Clinical success at 30 days and 9 months in the ACTIVE study ${ }^{9}$ was $88.2 \%$ and $90.4 \%$, respectively. There was an improvement in the Fontaine classification of claudication for the majority of patients, accompanied by significant and sustained improvements in walking speed, distance, and stair climbing. The patients' ability to walk without impairment improved by $41 \%$ from baseline (38.8\%) to 9 months (75.5\%). Patients also reported significant improvements in walking distance, walking speed, and ability to climb stairs at 30 days and 9 months when compared to baseline. The ankle brachial index/toe brachial index (ABI/TBI) values also significantly improved from $0.70 \pm 0.20$ at baseline to $0.96 \pm 0.20$ at 9 months $(P<0.001)$.

Overall, the ACTIVE study suggested that the Assurant stent is safe for use in the CIA of patients with claudication, and that the stent has an efficacy profile comparable to other currently available balloon-expandable iliac stents.

\section{Omnilink stent}

The Omnilink Elite ${ }^{\circledR}$ Vascular Balloon-Expandable stent (Abbott Vascular, Inc) is a flexible, balloon-expandable cobalt-chromium stent premounted on an OTW balloon. Its multilink design makes it a highly flexible stent that has increased conformability to tortuous anatomies. ${ }^{10}$ The stent balloon is a dual-layer, low-profile balloon designed to treat difficult-to-reach and heavily calcified lesions.

The safety and efficacy of the Omnilink stent were evaluated in the Mobility Study. ${ }^{11}$ In that study, 153 patients with iliac disease (202 lesions) were treated with the Omnilink stent. Target lesions were most often located in the CIA $(170 ; 84.2 \%)$. The mean reference diameter was $8.1 \mathrm{~mm}$, and mean lesion length was $21.8 \mathrm{~mm}$. Most lesions (90.9\%) showed moderate-to-severe calcification. Successful stent implantation with $<30 \%$ residual stenosis was achieved in $93.1 \%$ of lesions (189/202). After 9 months, the rate of major adverse events was $5.4 \%$, significantly below the primary end point goal of $19.5 \%(P<0.0001)$. Walking ability significantly improved, and the restenosis rate was $9.0 \%$ despite moderate-to-severe calcification in $90 \%$ of all lesions treated.

\section{Self-expanding stents}

Self-expanding stents consist of a flexible, fine mesh tubular prosthesis, which achieves its unconstrained diameter upon deployment. The prototypical wall stent is composed of elgiloy alloy wire mesh, relying on a predetermined springlike design to achieve the desired expansion, but which limits its radial strength. Newer-generation self-expanding stents are made of nitinol, which is a nickel-titanium alloy characterized by the property of thermal memory, which is a result of the varying crystal lattice structure of the alloy at different temperatures.

\section{Zilver stent}

The Zilver Vascular stent (Cook, Inc) is a self-expanding stent that is laser-cut from nitinol tubing. The Zilver stent is designed to be highly flexible and to have high radial strength. 
Its linear cell stent design potentially provides stable deployment by minimizing elongation and twisting.

The safety and efficacy of the Zilver stent were evaluated in a multicenter study published by Krol et al. ${ }^{12}$ In that study, 151 patients (177 lesions) were enrolled at 24 sites in the US. A majority of the lesions (50.8\%) were in the CIA, and 204 stents were placed in the 177 lesions. The acute procedural success rate was $98 \%$. Core laboratory analysis revealed that patency rates were high both after the procedure $(99.2 \%)$ and at 9-month follow-up (92.9\%). The 9-month patency rate for lesions treated with one stent was $95 \%$, and the patency rate for overlapping stents was $82 \%$. There were significant increases between the walking distances and speeds from scores before the procedure to those at 1-month and 9-month follow-up. There was a significant increase in mean ABI from before to after the procedure and at 1 - and 9-month follow-up. ${ }^{12}$ Subsequently, longer-term follow-up at 2 years suggested an overall patency of $90 \%$, with sustained improvement in ABI and Walking Impairment Questionnaire (WIQ) scores. ${ }^{13}$

\section{SMART stent}

The shape-memory alloy recoverable technology $\left(\mathrm{SMART}^{\circledR}\right.$, Cordis, Inc) self-expanding stent is composed of nitinol, with a total of 12 (six at each end) tantalum radiopaque markers. The delivery system consists of an inner shaft and an outer sheath locked together with a valve, with the self-expanding stent constrained in the space between. Radiopaque markers at the distal and proximal ends of the shaft allow fluoroscopic visualization.

The safety and efficacy of the SMART stent were evaluated in the CRISP-US Study. ${ }^{14}$ This multicenter, prospective, randomized trial enrolled 203 patients with symptomatic iliac artery stenosis and suboptimal results from balloon angioplasty. In this trial, 102 patients received the SMART stent and 101 received the Wallstent ${ }^{\mathrm{TM}}$. The acute procedural success rate was higher in the SMART stent group $(98.2 \%$ vs $87.5 \% ; P<0.002)$. The 9 -month composite end point rate was equivalent for the SMART stent and Wallstent (6.9\% vs $5.9 \%$ ), with low rates of restenosis $(3.5 \%$ vs $2.7 \%)$, death $(2.0 \%$ vs $0.0 \%)$, and revascularization $(2.0 \%$ vs $4.0 \%)$, respectively, in the two groups. Primary patency at 12 months was $94.7 \%$ and $91.1 \%$ with the SMART stent and Wallstent, respectively. Functional and hemodynamic improvement was also comparable between the groups. The frequency of major adverse events was also similar at 1 year (4.9\% vs 5.9\%).

\section{Absolute Pro stent}

The Absolute Pro Vascular Self-Expanding Stent System (Absolute Pro; Abbott, Inc) is a self-expanding nickel-titanium stent that is premounted on an OTW delivery system. It has 12 (six at each end of the stent) radiopaque markers made of a nickel-titanium alloy. The delivery system has a triaxial design, potentially helping with predictable stent deployment, thereby lowering the likelihood of "geographic miss."

The safety and effectiveness of the Absolute Pro stent were evaluated in one of two arms of the MOBILITY clinical study (the second arm of the study independently evaluated the Omnilink stent). ${ }^{15}$ A total of 151 subjects were enrolled in the Absolute Pro arm at 33 clinical sites in the US. Patients with $100 \%$ occlusions of the EIA were excluded. The stent was successfully implanted in $96.4 \%$ (186/193) of patients, and technical success on a per-lesion basis was $87.3 \%$ $(158 / 181)$. The walking distance mean score increased from $14.0 \% \pm 19.9 \%$ at baseline to $55.7 \% \pm 39.6 \%$ at 9 months. The walking speed and stair climbing mean scores also increased from $17.9 \% \pm 20.8 \%$ and $22.7 \% \pm 23.9 \%$, respectively, at baseline to $50.6 \% \pm 33.9 \%$ and $59.2 \% \pm 37.5 \%$ at 9 months. The majority of limbs, 95.9\% (141/147), had 9-month hemodynamic success, defined as TBI or ABI improvement by $\geq 0.1$ compared to baseline or deterioration by $\leq 0.15$ compared to postprocedure values. At 9 months, 93.9\% $(139 / 148)$ of limbs had improved by $\geq 1$ Rutherford clinical category. Restenosis, defined as $\geq 50 \%$ stenosis by duplex ultrasonography or arteriography, occurred in $8.4 \%$ (13/154) of lesions. The primary end point of major adverse events (death, myocardial infarction, clinically driven target lesion revascularization, and major amputation on the treated side) at 9 months was $6.1 \%(9 / 147)$. Overall, this study concluded that the Absolute Pro stent was safe and effective in patients with iliac disease.

\section{Lifestar stent}

The LifeStar ${ }^{\circledR}$ Vascular stent (Bard, Inc) is a self-expanding nitinol stent with a segmental repeating pattern and an open cell geometry with flared ends to help prevent dislocation or migration. Partial cuts around the circumference of the stent cylinder provide enhanced flexibility and allow segment-bysegment expansion. Each end of the stent has four radiopaque tantalum markers to facilitate accurate stent placement.

The LifeStar stent was evaluated in a prospective, multicenter, nonrandomized clinical study conducted at nine US sites. ${ }^{16}$ A total of 156 CIA or EIA lesions in 134 patients were included. Anatomic success (defined as $<30 \%$ residual stenosis) was achieved in $87.5 \%$. The primary patency rate at 9 months was $94 \%$ and this stent was successfully deployed in $95.1 \%$ of lesions. Target limb revascularization at 9 months was $11.2 \% ; 2.2 \%$ of patients underwent an amputation and $1.5 \%$ suffered major procedure-related bleeding. Overall, this 
study concluded that the Lifestar stent is safe and effective in patients with iliac disease.

\section{Covered stents}

A covered stent or stent graft is a metal stent lined with polytetrafluoroethylene (PTFE) or Dacron. Currently available covered stents for the iliac arteries include both selfexpanding and balloon-expandable platforms.

\section{Covered self-expanding stents}

The Viabahn ${ }^{\circledR}$ endoprosthesis (Gore, Inc; originally marketed under the name Hemobahn ${ }^{\circledR}$ ) is approved by the US Food and Drug Administration (FDA) for use in patients with symptomatic iliac artery lesions with reference vessel diameters ranging from $4 \mathrm{~mm}$ to $12 \mathrm{~mm}$. The Viabahn is a flexible, self-expanding endoluminal endoprosthesis, consisting of an expanded PTFE lining, with an external nitinol support extending along its entire length. The device is also available with a heparin bioactive surface, where the surface of the endoprosthesis is modified with covalently bound, bioactive heparin. The endoprosthesis is compressed and attached to a dual-lumen delivery catheter to facilitate delivery. ${ }^{17}$

A prospective evaluation of the Viabahn stent in 61 iliac arteries provided primary patency rates for the iliac arteries of $98 \%$ at 6 months and $91 \%$ at 12 months. ${ }^{18}$ The mean lesion length was $6.9 \mathrm{~cm}$. Primary technical success, with correct placement and antegrade flow through the prosthesis, was achieved in all patients. Embolization to distal arteries was observed after stent graft placement in two out of five cases where an iliac artery occlusion was treated. No device- or procedure-related deaths were reported.

\section{Covered balloon-expandable stents}

The iCAST ${ }^{\mathrm{TM}}$ Balloon-Expandable covered stent (Atrium, Inc) is FDA $510(\mathrm{k})$ approved for treatment of tracheobronchial strictures and is commonly used off label in the iliac arteries as well. The device utilizes film-cast encapsulation technology covering its stainless steel stent with a thin outer and inner PTFE coating that protects the struts from contacting the luminal wall and helps evenly distribute radial expansion stress during balloon deployment. ${ }^{19}$

The Covered Versus Balloon-Expandable Stent Trial $(\mathrm{COBEST})^{20}$ was a prospective, multicenter, randomized controlled trial that included 125 patients (168 iliac arteries) with severe iliac occlusive disease who were randomized to receive either the V12 covered balloon-expandable stent (which is similar to the current iCAST stent) or a bare-metal stent (BMS). Lesions treated with a covered stent were significantly more likely to remain free from binary restenosis compared to those treated with a BMS (hazard ratio [HR]: 0.35; 95\% confidence interval [CI]: 0.15-0.82). Freedom from occlusion was not statistically different (HR: 0.28; 95\% CI: 0.07-1.09). Subgroup analyses demonstrated a significant improvement in freedom from binary restenosis for covered stents in TASC C and D lesions (HR: 0.14; 95\% CI: 0.04-0.44). This difference was not demonstrated for TASC B lesions (HR: 0.75; 95\% CI: 0.24-2.39). There was also a lower rate of repeat revascularization in the covered stent group compared with the BMS group (odds ratio [OR]: 0.21 ; 95\% CI: $0.07-0.64)$. Most of the reinterventions were performed between 12 months and 18 months. The amputation rate was similar and low between the two groups. Overall, $\mathrm{COBEST}^{20}$ demonstrated that both covered stents and BMSs produce similar and acceptable results for TASC B lesions. However, covered stents may be associated with a lower rate of restenosis for TASC C and D lesions compared to BMSs on longer-term follow-up.

The iCAST covered stent was also evaluated in the prospective, multicenter, nonrandomized, one-arm iCARUS trial $^{21}$ based on a prespecified performance metric derived from studies of FDA-approved iliac stent devices for treating iliac artery stenoses. This study enrolled 165 patients with de novo or restenotic lesions in the CIAs and/or EIAs across 25 sites. The composite end point of the occurrence of death within 30 days, target site revascularization within 9 months, or restenosis detected on duplex ultrasonography of the iliac artery (or angiography done in lieu of ultrasonography) at 9 months was observed in $8.1 \%$ of patients, which was significantly lower than the performance metric of $16.6 \%$. There were no deaths within 30 days. The target lesion revascularization rate within 9 months was $2.9 \%$. Overall, the iCARUS data suggested that the iCast covered stent was safe and effective for iliac artery revascularization.

Outcomes of covered balloon-expandable stents versus balloon-expandable BMSs were also reported from a retrospective series of 162 patients with common iliac and aortic occlusive disease. ${ }^{22}$ In that study, BMSs were used in 190 arteries and covered balloon-expandable stents were used in 64 arteries. There was no difference in age, sex, or TASC classification between the two groups. Mean follow-up was $22 \pm 16$ months. Patients in the covered stent group were more likely to require repeat intervention (HR: $2.5 ; 95 \%$ CI: $1.2-5.3 ; P=0.009)$, and primary, assisted, as well as secondary patency were significantly better in the BMS group. TASC classification did not predict need for reintervention in either group.

Overall, given these conflicting data on covered stents, their use in aortoiliac disease is currently reserved for special circum- 
stances such as perforations and clot or aneurysm exclusion. Further data will be necessary to better delineate circumstances that favor use of a covered stent in the iliac arteries.

Tables 1 and 2 further summarize existing studies on major available iliac stents and their individual technical aspects.

\section{Technical aspects of iliac artery endovascular interventions}

Endovascular treatment of iliac artery obstructive disease is usually performed via femoral arterial access, using either a retrograde- or antegrade-crossover approach. While retrograde access is technically easier, lesion visualization is superior with a crossover sheath. Radial or brachial artery access is also feasible for endovascular treatment of the iliac arteries - most currently available peripheral balloons and stents can reach the proximal to mid iliac arteries if the left radial artery is used for sheath access. ${ }^{23,24}$

While a number of technical factors exist in the treatment of iliac artery stenosis, the most frequently encountered issues include the following: 1) treatment of iliac artery bifurcation disease; 2) outcomes of iliac artery occlusions and TASC C/D lesions; 3 ) choice of stent type during the endovascular intervention; and 4) treatment of iliac artery in-stent restenosis.

\section{Treatment of iliac artery bifurcation disease}

Iliac artery bifurcation disease is a common problem during endovascular intervention, representing $\sim 10 \%$ of all iliac interventions. ${ }^{25}$ Most commonly, the ostia of the bilateral common iliac arteries are diseased, thereby necessitating bilateral stent placement. ${ }^{26,27}$ Other anatomic issues include unilateral ostial disease with the potential for plaque shift into an otherwise angiographically normal contralateral iliac artery and presence of atherosclerotic disease at the origin of the internal iliac artery. Limited data suggest that stenting of a nondiseased contralateral iliac artery is associated with excellent long-term patency and less-recurrent stenosis than treatment of a diseased iliac artery origin. ${ }^{28} \mathrm{~A}$ few data are available regarding the outcomes of internal iliac artery patency after crossing the origin of the internal iliac artery; in general, care should be taken to avoid stenting across the internal iliac artery origin unless necessary.

When stents are placed at the bilateral CIAs, treatment approaches can include extension of the stents into the distal aorta, thereby recreating the bifurcation, or so-called "V"-stenting, whereby the proximal edges of the stents are placed at the bifurcation. The presence of distal abdominal aortic disease may necessitate recreation of the bifurcation, while a relatively normal distal aorta may make V-stenting possible. One study ${ }^{29}$ has suggested that stent overlap during deployment may affect long-term patency, possibly due to altered flow dynamics at the reconstructed bifurcation. V-stenting also has the advantage of making future crossover sheath access less technically challenging if additional endovascular interventions are required in the future.

In the largest study ${ }^{25}$ of long-term outcomes after stenting of aortoiliac bifurcation disease, 190 patients were followed for up to 5 years as part of a multicenter registry. The overall patency was $87 \%$ at 1 year and $73 \%$ at 5 years. The long-term patency of bifurcation lesions was slightly lower than that of nonbifurcation lesions ( $73 \%$ vs $78 \%$ ). On multivariable analysis, female sex and presence of residual stenosis after stenting were associated with restenosis; there was no effect of stent type on outcomes. In comparison, other studies have suggested a possible benefit of covered stents in the treatment of aortoiliac bifurcation disease: one single-center study reported a $92 \%$ primary patency of covered stents at 2 years, versus only $62 \%$ for noncovered stents. ${ }^{30}$ The results of the COBEST study ${ }^{20}$ may also support the use of covered stents for treatment of aortoiliac bifurcation disease, because many of these lesions may be classified as TASC C/D based on bilateral involvement and frequent presence of occlusion on at least one side.

\section{Treatment of iliac artery occlusions and complex aortoiliac disease}

Iliac artery occlusions represent a technical challenge for endovascular interventions, as entry into the true lumen should ideally be achieved with preservation of both the aortic bifurcation and the internal iliac artery origin. In addition, long-segment EIA occlusions that extend near or into the common femoral artery origin may necessitate a hybrid treatment approach, with a combined common femoral endarterectomy and stenting of the EIA. ${ }^{31}$

Iliac artery occlusions may be crossed either antegrade or retrograde. Antegrade crossing may be associated with higher initial procedural success, although the outcomes may be dependent partly on the site of the occlusion and reconstitution. ${ }^{32}$ In the case of an ostial or proximal CIA occlusion, sheath support may be difficult, thereby necessitating a brachial or radial artery approach or a primary attempt via retrograde access. In cases of a subintimal tracking from both directions, a modified controlled antegrade and retrograde subintimal tracking (CART) technique may facilitate reentry; other options include the use of fluoroscopy- or ultrasonography-guided reentry. ${ }^{33,34}$

The TASC II guidelines and the recently published modifications classify iliac artery lesions as types A-D, with types $\mathrm{B}, \mathrm{C}$, and D including iliac artery occlusions. ${ }^{35}$ Although 
Table 3 Advantages and disadvantages of iliac artery stent types

\begin{tabular}{|c|c|c|}
\hline Stent type & Advantages & Disadvantages \\
\hline Self-expanding & $\begin{array}{l}\text { - Highly flexible } \\
\text { - May be favored in external } \\
\text { iliac artery lesions }\end{array}$ & $\begin{array}{l}\text { - Less predictable } \\
\text { deployment than } \\
\text { balloon-expandable } \\
\text { stents }\end{array}$ \\
\hline $\begin{array}{l}\text { Balloon- } \\
\text { expandable }\end{array}$ & $\begin{array}{l}\text { - Increased radial strength } \\
\text { - Predictable placement } \\
\text { - May be favored in ostial or } \\
\text { calcified lesions }\end{array}$ & $\begin{array}{l}\text { - Less flexible than } \\
\text { self-expanding stents }\end{array}$ \\
\hline Covered stent & $\begin{array}{l}\text { - Excludes plaque/thrombus } \\
\text { - May be associated with } \\
\text { improved patency for TASC } \\
\text { C/D lesions }\end{array}$ & $\begin{array}{l}\text { Requires a larger } \\
\text { sheath size than } \\
\text { noncovered stents }\end{array}$ \\
\hline
\end{tabular}

Abbreviation: TASC, Trans-Atlantic Intersociety Consensus.

original recommendations suggested that TASC C/D lesions should be treated with surgery, a number of observational studies have suggested acceptable rates of technical success and long-term patency after endovascular treatment of TASC C/D lesions. In a single-center study of 89 patients with iliac occlusions, technical success was achieved in $91 \%$ of cases. The 3-year primary patency was $76 \%$, with a secondary patency rate of $90 \% .{ }^{36}$ In a single-center comparison of iliac occlusions treated with endovascular therapy vs aortobifemoral bypass grafting, the primary patency of endovascular therapy was lower during 6-year follow-up (73\% vs $91 \%)$, but the rates of secondary patency were similar $(85 \%$ vs $98 \%) .{ }^{37}$ Recent systematic reviews have confirmed that the technical success rates are high for endovascular treatment of extensive aortoiliac disease, with lower long-term patency compared to surgery, but that restenosis can in most cases be treated with a second endovascular procedure. ${ }^{38,39}$

\section{Choice of stent type}

Although few comparative studies exist to determine the relative efficacy of one iliac stent compared with others, several anatomic subsets may favor use of one stent type over another. Table 3 lists relative advantages and disadvantages of different types of iliac stents.

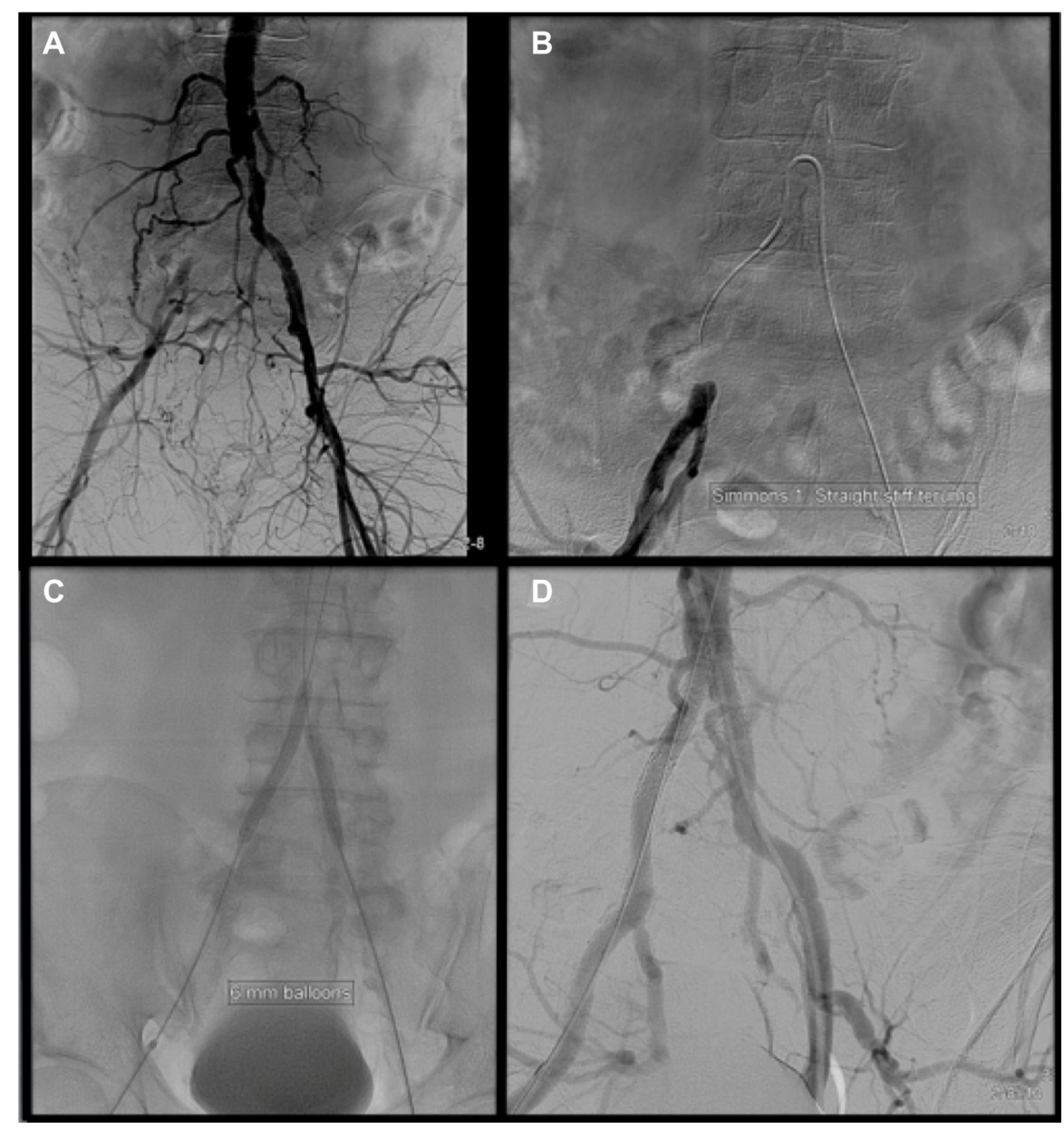

Figure I Balloon-expandable stent placement for treatment of bilateral common iliac artery disease.

Notes: (A) The right common iliac artery is occluded near the ostium, with moderate disease of the left common iliac artery origin. (B) The occlusion was crossed antegrade, using a Simmons I catheter and a straight-stiff glidewire. (C) Bilateral kissing balloon angioplasty was performed for predilation. (D) Bilateral balloon-expandable stents were placed in the common iliac arteries, with a short self-expanding stent extended into the right external iliac artery. 
For the iliac arteries, a balloon-expandable stent is often preferred for treatment of calcified and/or ostial common iliac lesions (Figure 1). The increased radial force and predictable placement of balloon-expandable stents make them a better choice for precise treatment of a focal lesion in an area with less tortuosity and without repetitive external trauma (such as the inguinal ligament and across joints). The excellent hoop strength also makes balloon-expandable stents the preferred device for ostial and calcified lesions. As a routine, the device size is matched to the anticipated vessel diameter. Balloon-expandable stents can be dilated 2-3 mm beyond their nominal size with appropriate balloon oversize, although, in some cases, this may result in shortening of the overall stented length. In some cases of iliac bifurcation disease, balloon-expandable stents may need to be deployed simultaneously in order to minimize the risk of plaque shift and effectively reconstruct the iliac bifurcation.
Self-expanding stents are better suited for tortuous vessels, especially in areas of permanent external forces such as the EIA (Figure 2). Because of the inability for additional dilatation of the device, precise device/target vessel size match is required. These stents guarantee precise placement only on the end that is deployed first, but newer-generation nitinol self-expanding stents exhibit minimal foreshortening at human body temperature and have a more predictable length once deployed in the body. As a rule, the leading end of the device is always maneuvered just past the planned landing zone, allowing for fine adjustments and retraction during its deployment. The final length of a self-expanding stent is difficult to predict in vivo. For this reason, self-expanding stents can cover longer lesions but are not practical for treating focal disease. Limited radiopacity is another limitation of nitinol stents; for this reason, all available devices have radiopaque

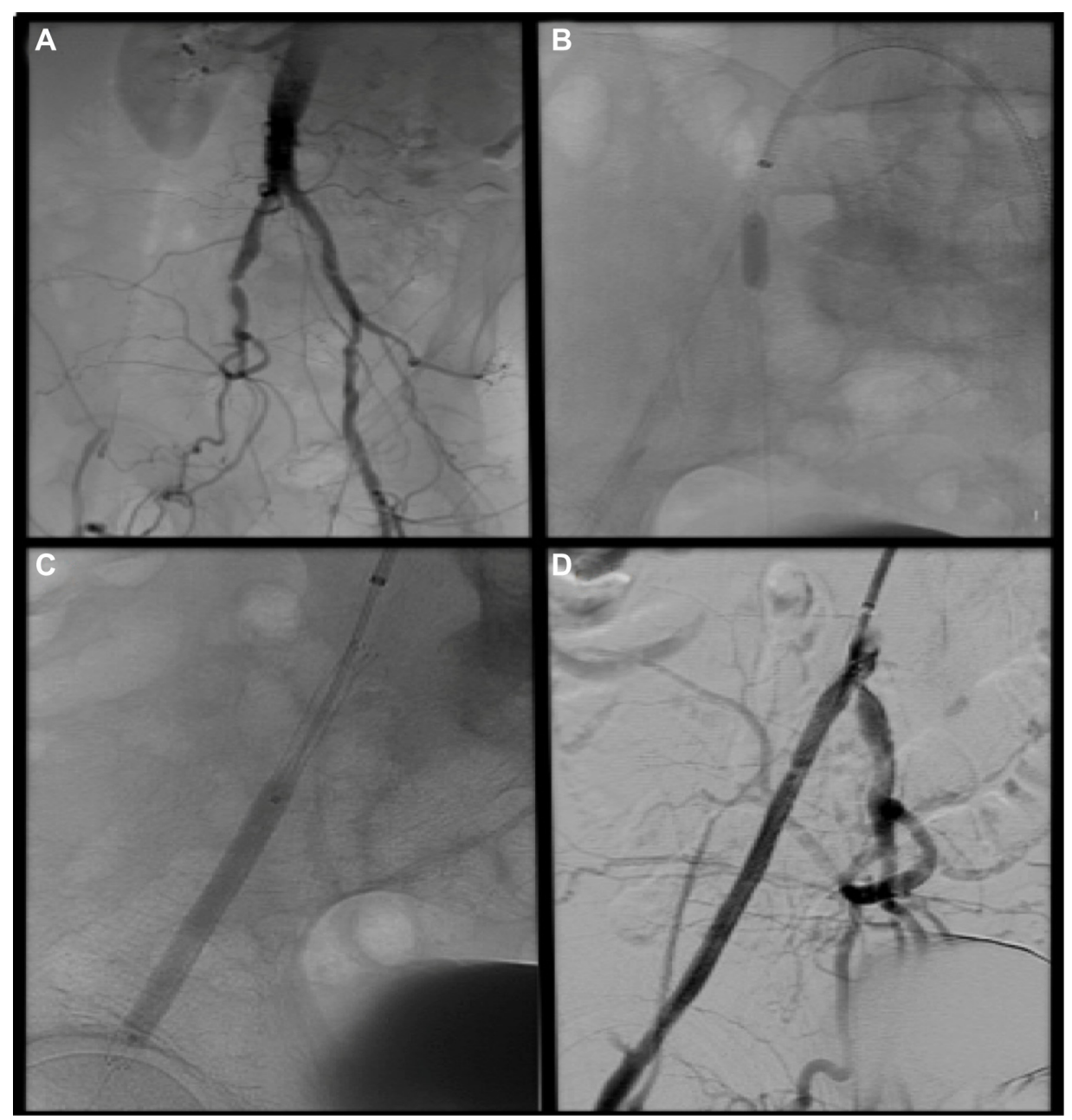

Figure 2 Self-expanding stent placement for treatment of an occluded external iliac artery.

Notes: (A) The right external iliac artery is occluded, with reconstitution in the distal artery near the origin of the common femoral artery. There is also significant stenosis at the origin of the right internal iliac artery. (B) The occlusion was crossed antegrade. Balloon angioplasty of the internal iliac artery origin was performed to minimize the chance of internal iliac artery occlusion. (C) A self-expanding stent was placed across the external iliac artery. (D) Final angiography demonstrated excellent angiographic result with preservation of the internal iliac artery origin. 


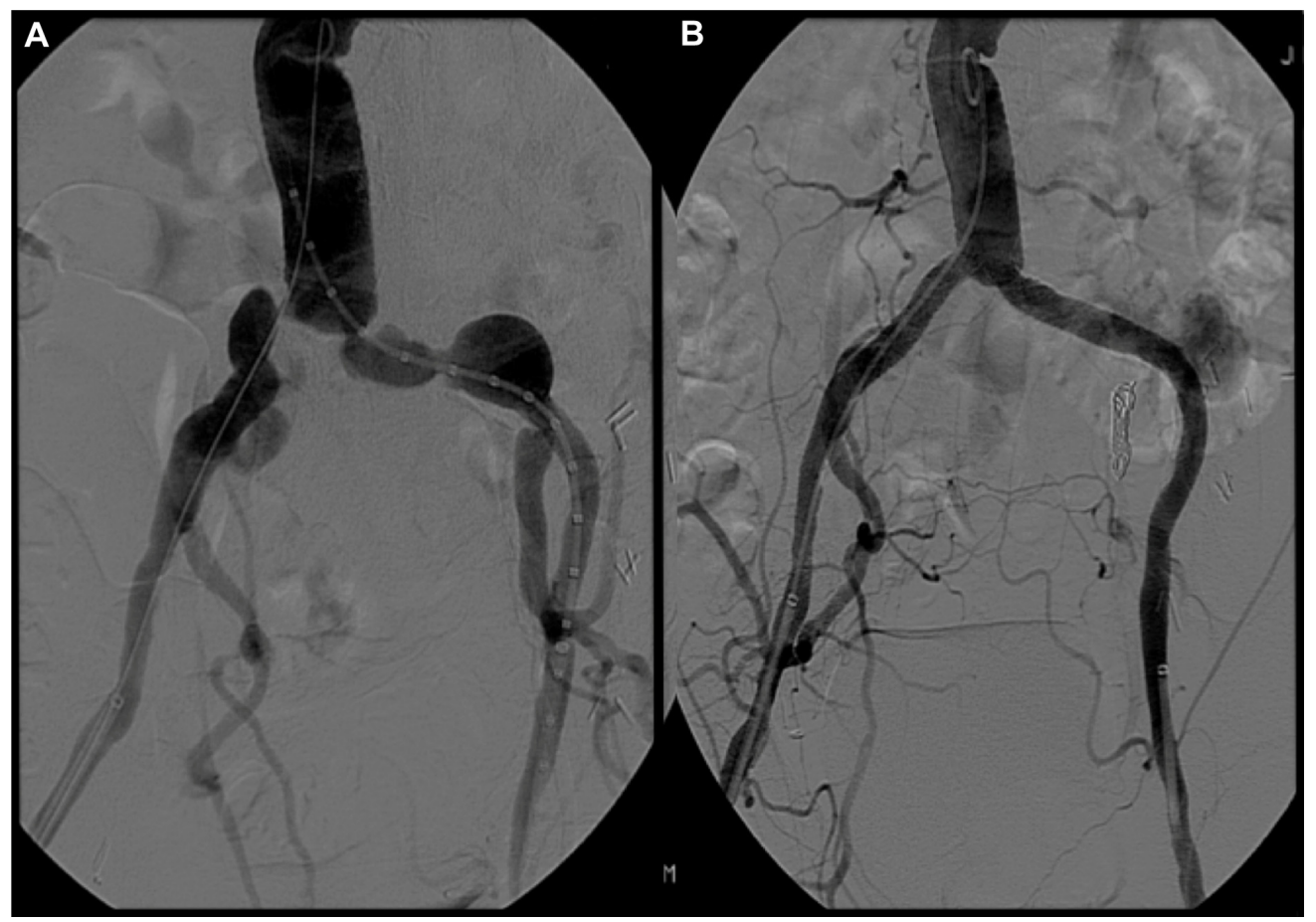

Figure 3 Revascularization of aneurysmal common iliac arteries with covered stents.

Notes: (A) The bilateral common iliac arteries demonstrate both significant stenosis and aneurysmal dilatation. (B) The left internal iliac artery was treated with coil embolization, and bilateral covered stent placement resulted in excellent angiographic result and exclusion of the common iliac artery aneurysms.

markers to facilitate accurate positioning and subsequent radiographic evaluation.

Given the PTFE lining, covered stents may overcome some limitations of standard stent designs by introducing a mechanical barrier between intimal hyperplasia and the arterial lumen. This covering potentially also prevents migration of macrophages in the vascular wall, which are attracted by proinflammatory mediators secreted by the damaged vessel wall. These macrophages release further cytokines, metalloproteinases, and growth factors that contribute to initiation of the restenotic process. Currently, given the lack of conclusive data on their use, covered stents are largely reserved for treating iliac perforations, thrombus/aneurysm exclusion, and iliac stent restenosis, although an increasing number of common iliac lesions are treated with covered balloon-expandable stents (Figure 3 ).

\section{Treatment of iliac artery in-stent restenosis}

Although endovascular interventions to iliac arteries are associated with excellent long-term patency, a subset of patients may develop symptomatic restenosis. The overall outcomes and treatment of such patients, however, is not well defined. In a single-center study ${ }^{40}$ of 24 patients with 41 in-stent restenotic lesions, patients were treated with balloon angioplasty and a high rate $(66 \%)$ of additional stent placement. The 12 -month primary patency rate was $82 \%$, with a primary assisted patency rate of $90 \%$. These initial results suggest reasonable outcomes of repeat balloon angioplasty with provisional stenting for treatment of iliac artery in-stent restenosis.

The recent availability of paclitaxel-coated balloons has also led to initial reports of use of this technology for treatment of iliac artery in-stent restenosis. In a study of 18 patients, ${ }^{41}$ drug-eluting balloon angioplasty was associated with a 12 -month primary patency of $71 \%$, which was similar to the primary patency after treatment with a standard balloon (76\%). A smaller study of six patients also suggested excellent 2-year patency after use of drug-coated balloons for treatment of iliac artery in-stent restenosis. ${ }^{42}$ Given the small size of these two studies, additional larger studies will be necessary to prove the utility of drugcoated balloons in the treatment of iliac artery in-stent restenosis.

\section{Conclusion and future directions}

Overall, iliac stent choice can be largely categorized into choosing either a balloon-expandable or self-expanding stent based on lesion characteristics (ie, calcified, fibrous, soft, eccentric, concentric, focal, diffuse, etc), access site, introducer size, vessel tortuosity, and lesion location. Given the lack of randomized comparative effectiveness data and the relatively similar patency results of existing second-generation 
iliac stents in these regulatory single-arm trials; stent choice is largely based on operator experience, familiarity with particular products, ease of deployment, availability, and cost.

Further efforts are needed to establish the comparative effectiveness of available iliac stents, as well as to identify optimal therapies for iliac artery bifurcation disease, long segment occlusions, and iliac artery in-stent restenosis.

\section{Disclosure}

Dr Armstrong is a consultant to Abbott Vascular, Medtronic, Merck, Pfizer, and Spectranetics. The other authors report no conflicts of interest in this work.

\section{References}

1. Aboyans V, Desormais I, Lacroix P, Salazar J, Criqui MH, Laskar M. The general prognosis of patients with peripheral arterial disease differs according to the disease localization. $J$ Am Coll Cardiol. 2010;55:898-903.

2. Selvin E, Erlinger TP. Prevalence of and risk factors for peripheral arterial disease in the United States: results from the National Health and Nutrition Examination Survey, 1999-2000. Circulation. 2004;110:738-743.

3. Kashyap VS, Pavkov ML, Bena JF, et al. The management of severe aortoiliac occlusive disease: endovascular therapy rivals open reconstruction. J Vasc Surg. 2008;48:1451-1457, 1457.e1-e3.

4. Indes JE, Mandawat A, Tuggle CT, Muhs B, Sosa JA. Endovascular procedures for aorto-iliac occlusive disease are associated with superior short-term clinical and economic outcomes compared with open surgery in the inpatient population. JVasc Surg. 2010;52:1173-1179,1179. e1.

5. Bosch JL, Hunink MG. Meta-analysis of the results of percutaneous transluminal angioplasty and stent placement for aortoiliac occlusive disease. Radiology. 1997;204:87-96.

6. Rees CR, Palmaz JC, Garcia O, et al. Angioplasty and stenting of completely occluded iliac arteries. Radiology. 1989;172:953-959.

7. Palmaz JC. Balloon-expandable intravascular stent. AJR Am J Roentgenol. 1988;150:1263-1269.

8. Stockx L, Poncyljusz W, Krzanowski M, et al; MELODIE Investigators. Express LD vascular stent in the treatment of iliac artery lesions: 24-month results from the MELODIE trial. J Endovasc Ther. 2010;17:633-641.

9. Molnar RG, Gray WA, Investigators AT. Sustained patency and clinical improvement following treatment of atherosclerotic iliac artery disease using the assurant cobalt iliac balloon-expandable stent system. J Endovasc Ther. 2013;20:94-103.

10. Kastrati A, Mehilli J, Dirschinger J, et al. Intracoronary stenting and angiographic results: strut thickness effect on restenosis outcome (ISAR-STEREO) trial. Circulation. 2001;103:2816-2821.

11. Abbott Vascular [webpage on the Internet]. Omnilink Elite ${ }^{\circledR}$ Vascular Balloon-Expandable Stent System. Available from: http://www. abbottvascular.com/docs/ifu/peripheral_intervention/eIFU_Omnilink_ Elite.pdf. Accessed July 25, 2015.

12. Krol KL, Saxon RR, Farhat N, et al. Clinical evaluation of the zilver vascular stent for symptomatic iliac artery disease. JVasc Interv Radiol. 2008; 19:15-22.

13. Jaff MR, Katzen BT. Two-year clinical evaluation of the zilver vascular stent for symptomatic iliac artery disease. J Vasc Interv Radiol. 2010;21:1489-1494.

14. Ponec D, Jaff MR, Swischuk J, et al; CRISP Study Investigators. The nitinol SMART stent vs Wallstent for suboptimal iliac artery angioplasty: CRISP-US trial results. J Vasc Interv Radiol. 2004;15:911-918.
15. Abbott Vascular [webpage on the Internet]. Absolute Pro ${ }^{\circledR}$ Vascular Self-Expanding Stent System. Available from: http://www.abbottvascular.com/docs/ifu/peripheral_intervention/eIFU_Absolute_Pro.pdf. Accessed July 25, 2015.

16. Bard Peripheral Vascular, Inc [webpage on the Internet]. LifeStar ${ }^{\mathrm{TM}}$ Vascular Stent System Ordering Information. Available from: http:// www.bardpv.com/wp-content/uploads/2013/07/S120118-R0-LifeStarVascular-Sales-Sheet.pdf. Accessed July 25, 2015.

17. GORE $^{\circledR}$ VIABAHN ${ }^{\circledR}$ Endoprosthesis [webpage on the Internet]. GORE ${ }^{\circledR}$ VIABAHN ${ }^{\circledR}$ Endoprosthesis with Heparin Bioactive Surface. Available from: http://www.goremedical.com/resources/dam/assets/MD132069. pdf. Accessed July 25, 2015.

18. Lammer J, Dake MD, Bleyn J, et al. Peripheral arterial obstruction: prospective study of treatment with a transluminally placed self-expanding stentgraft. International Trial Study Group. Radiology. 2000;217:95-104.

19. Atrium [webpage on the Internet]. Atrium ICAST ${ }^{\mathrm{TM}}$ Balloon Expandable Covered Stent. Available from: http://www.atriummed.com/en/ interventional/icast.asp. Accessed July 25, 2015.

20. Mwipatayi BP, Thomas S, Wong J, et al; Covered Versus Balloon Expandable Stent Trial (COBEST) Co-investigators. A comparison of covered vs bare expandable stents for the treatment of aortoiliac occlusive disease. J Vasc Surg. 2011;54:1561-1570.

21. Endovascular Today [webpage on the Internet]. Atrium's iCast Covered Stent in Iliac Treatment Supported by iCARUS Study. Available from: http://evtoday.com/2012/10/atriums-icast-covered-stent-in-iliactreatment-supported-by-icarus-study. Accessed July 25, 2015.

22. Humphries MD, Armstrong E, Laird J, Paz J, Pevec W. Outcomes of covered versus bare-metal balloon-expandable stents for aortoiliac occlusive disease. J Vasc Surg. 2014;60:337-343.

23. Cortese B, Trani C, Lorenzoni R, et al. Safety and feasibility of iliac endovascular interventions with a radial approach. Results from a multicenter study coordinated by the Italian Radial Force. Int J Cardiol. 2014;175:280-284.

24. Millon A, Della Schiava N, Brizzi V, et al. The antegrade approach using transbrachial access improves technical success rates of endovascular recanalization of TASC C-D aortoiliac occlusion in case of failed femoral access. Ann Vasc Surg. 2015;29(7):1346-1352.

25. Aihara $\mathrm{H}$, Soga $\mathrm{Y}$, Iida $\mathrm{O}$, et al; REAL-AI Registry Investigators. Longterm outcomes of endovascualr therapy for aortoiliac bifurcations in the real-AI registry. $J$ Endovasc Ther. 2014;21:25-33.

26. Mendelsohn FO, Santos RM, Crowley JJ, et al. Kissing stents in the aortic bifurcation. Am Heart J. 1998;136:600-605.

27. Scheinert D, Schröder M, Balzer JO, Steinkamp H, Biamino G. Stentsupported reconstruction of the aortoiliac bifurcation with the kissing balloon technique. Circulation. 1999;100:II295-II300.

28. Mohamed F, Sarkar B, Timmons G, Mudawi A, Ashour H, Uberoi R. Outcomes of "kissing stents" for aortoiliac atherosclerotic disease, including the effect on the non-diseased contralateral iliac limb. Cardiovasc Intervent Radiol. 2002;25:474-475.

29. Greiner A, Muhlthaler H, Neuhauser B, et al. Does stent overlap influence the patency rate of aortoiliac kissing stents? J Endovasc Ther. 2005;12:696-703.

30. Sabri SS, Choudhri A, Orgera G, et al. Outcomes of covered kissing stent placmeent compared with bare metal stent placmeent in the treatment of atherosclerotic occlusive disease at the aortic bifurcation. JVasc Interv Radiol. 2010;21:995-1003.

31. Piazza M, Ricotta JJ, Bower TC, et al. Iliac artery stenting combined with open femoral endarterectomy is as effective as open surgical reconstruction for severe iliac and common femoral occlusive disease. J Vasc Surg. 2011;54:402-411.

32. Ozkan U, Oguzkurt L, Tercan F. Technique, complication, and long-term outcome for endovascular treatment of iliac artery occlusion. Cardiovasc Intervent Radiol. 2010;33:18-24.

33. Rogers RK, Tsai T, Casserly IP. Novel application of the "CART" technique for endovascular treatment of external iliac artery occlusions. Catheter Cardiovasc Interv. 2010;75:673-678. 
34. Baker AC, Humphries MD, Noll RE, et al. Technical and early outcomes using ultrasound-guided reentry for chronic total occlusions. Ann Vasc Surg. 2015;29:55-62.

35. The TASC Steering Committee, Jaff MR, White CJ, et al. An update on methods for revascularization and expansion of the TASC lesion classification to include below-the-knee arteries: a supplement to the inter-society consensus for the management of peripheral arterial disease (TASC II). J Endovasc Ther. 2015;22:657-671.

36. Leville CD, Kashyap VS, Clair DG, et al. Endovascular management of iliac artery occlusions: extending treatment to TransAtlantic inter-society consensus class C and D patients. J Vasc Surg. 2006;43:32-39.

37. Sachwani GR, Hans SS, Khoury MD, et al. Results of iliac stenting and aortofemoral grafting for iliac artery occlusions. J Vasc Surg. 2013;57:1030-1037.

38. Jongkind V, Akkersdijk GJ, Yeung KK, Wisselink W. A systematic review of endovascular treatment of extensive aortoiliac occlusive disease. J Vasc Surg. 2010;52:1376-1383.
39. Indes JE, Pfaff MJ, Farrokhyar F, et al. Clinical outcomes of 5358 patients undergoing direct open bypass or endovascular treatment for aortoiliac occlusive disease: a systematic review and meta-analysis. J Endovasc Ther. 2013;20:443-455.

40. Javed U, Balwanz CR, Armstrong EJ, et al. Mid-term outcomes following endovascular re-intervention for iliac artery in-stent restenosis. Catheter Cardiovasc Interv. 2013;82:1176-1184.

41. Stahlhoff S, Donas KP, Torsello G, Osada N, Herten M. Drug-eluting versus standard balloon angioplasty for iliac stent restenosis: midterm results. J Endovasc Ther. 2015;22:314-318.

42. Troisi N, Ercolini L, Peretti E, et al. Drug-eluting balloons to treat iliac in-stent restenosis. Ann Vasc Surg. 2015;29:e3-e6.
Vascular Health and Risk Management

\section{Publish your work in this journal}

Vascular Health and Risk Management is an international, peerreviewed journal of therapeutics and risk management, focusing on concise rapid reporting of clinical studies on the processes involved in the maintenance of vascular health; the monitoring, prevention and treatment of vascular disease and its sequelae; and the involvement of

\section{Dovepress}

metabolic disorders, particularly diabetes. This journal is indexed on PubMed Central and MedLine. The manuscript management system is completely online and includes a very quick and fair peer-review system, which is all easy to use. Visit http://www.dovepress.com/ testimonials.php to read real quotes from published authors. 